\title{
Inhalt, Vol. 11, No. 2, 1988
}

\section{Contents}

Impressum 64

Szuwart, U.; König, H.-J.; Bennefeld, H.; Weritz, Ch.;

Kleinhans, G. (Münster)

Klinik der hypophysären Metastasierungen 66

Informationen für die Klinik 70

Holtkamp, W.; Wuttke, W.; Nagel, G. A.;

Blossey, H. Ch. (Göttingen)

Vergleichende Untersuchungen zum Prolaktin-, Östrogen-, Gestagen- und Androgenrezeptorgehalt mensch-

licher Mammakarzinome 71

Meyer-Lindau, F.; Pfister, E.; Gyr, N.; Obrecht, J. P.

(Basel)

Randomisierte Doppelblindstudie über die analgetische

Wirkung von Caerulein und Morphin bei chronischen

Tumorschmerzen 77

Wowra, B.; Mentrup, E.; Zeller, W. J.; Strieker, H.;

Sturm, V. (Heidelberg)

CT-Kinetik intratumoraler Liposomendepots 81

Holtkamp, W.; Wuttke, W.; Nagel, G. A.; Michel, U.; Rauschecker, H. (Göttingen)

Pathophysiologie der Hyperprolaktinämie beim Mamma-

karzinom 86

Hinweise für Autoren 103

Buchbesprechungen 104

Kurzmitteilung

Görg, C; Görg, K.; Pflüger, K.-H.; Havemann, K.;

Glanz, H.; Kleinsasser, O. (Marburg)

Therapie des adenoidzystischen Karzinoms mit Cisplatin, Etoposid und Vindesin 106

Imprint 64

Szuwart, U.; König, H.-J.; Bennefeld, H.; Weritz, Ch.;

Kleinhans, G. (Münster)

Pathology of Pituitary Gland Metastases $\quad 66$

Clinical Information 70

Holtkamp, W.; Wuttke, W.; Nagel, G. A.; Blossey, H. Ch. (Göttingen)

Comparative Studies on the Prolactin, Estrogen, Gesta

gen and Androgen Receptor Content of Human Breast

Carcinomas 71 
Meyer-Lindau, F.; Pfister, E.; Gyr, N.; Obrecht, J. P.

(Basel)

A Randomized Double-Blind Study of the Analgetic

Effect of Caerulein and Morphine in Chronic Tumor

Pain 77

Wowra, B.; Mentrup, E.; Zeller, W. J.; Strieker, H.;

Sturm, V. (Heidelberg)

CT-Kinetics of Intraneoplastic Deposits of Liposomes . . 81

Holtkamp, W.; Wuttke, W.; Nagel, G. A.; Michel, U.; Rauschecker, H. (Göttingen)

Pathophysiology of Hyperprolactinemia in Breast Cancer

Patients 86

Instructions for Authors 103

Book Reviews 104

Short Communication

Görg, C; Görg, K.; Pflüger, K.-H.; Havemann, K.;

Glanz, H.; Kleinsasser, O. (Marburg)

Cisplatin, Etoposide, and Vincristine for Adenoid Cystic

Carcinoma of the Head and Neck 106

Beilagenhinweis: Diese Ausgabe enthält eine Beilage der Firma Mack. Wir bitten um freundliche Beachtung.

Bibliographischer Hinweis: Inhaltsverzeichnisse dieser Zeitschrift erscheinen regelmäßig in current contents ${ }^{\circledR}$ sowie in anderen bibliographischen Diensten. 